\title{
Métodos ativos de ensino aliados com tecnologia para a prática de ensino: um relato de experiência
}

\author{
Felipe Theodoro Guimarães ${ }^{1}$, Maici Duarte Leite $^{1}$, Francisco Reinaldo ${ }^{1}$, Giani Ito ${ }^{1}$ \\ ${ }^{1}$ Departamento Acadêmico de Informática \\ Observatório Paranaense de Tecnologias de Informação e Comunicação e Sociedade \\ Grupo de pesquisa em Eng. do Conhecimento \& Pensamento Computacional \\ Universidade Tecnológica Federal do Paraná - (UTFPR) \\ Caixa Postal 135 - 85.601-970 - Francisco Beltrão - PR - Brasil



\begin{abstract}
The technological advance transforms society, which in turn changes the school environment. The purpose of this study is to present an experience report using technology in benefit of education through the active teaching methodologies that make students the main actor in the teaching-learning process and place the teacher as an enabler and tutor of the construction of the knowledge of your students. For this research was carried out a survey of some teaching methodologies, and also described a report teaching experience in which some of the methodologies addressed in the text are applied, in order to study and analyze the behavior of the students in relation to the traditional classes.
\end{abstract}

Resumo. O avanço tecnológico transforma a sociedade, que por sua vez passa a transformar o ambiente escolar. Este artigo apresenta um relato de experiência com o uso da tecnologia a favor da educação por meio das metodologias ativas de ensino, tais como a Aprendizagem Baseada em Times, que tornam os alunos protagonistas no processo de ensino-aprendizagem, enquanto o professor tornase promotor e tutor da construção do conhecimento de seus alunos. Para esta pesquisa foi realizado um estudo de metodologias de ensino, e aplicação em ambiente escolar, a fim de estudar e analisar o comportamento dos alunos em relação às aulas com propostas de ensino tradicionais.

\section{Introdução}

As novas tecnologias desafiam os professores em suas práticas docentes, pois o uso de smartphones e tablets em sala de aula já é um fato a ser considerado. Essa realidade emergente traz uma reflexão pertinente, ao uso de tecnologias aplicadas à educação, bem como, a inserção dos recursos tecnológicos em sala de aula.

Pode-se notar que as influências tecnológicas na sociedade provocam novos comportamentos, tranformando o relacionamento das pessoas e o modo como se comunicam [Reinaldo et al. 2016] [Fiorio et al. 2014], um exemplo, é o excessivo uso do computador e do smartphone, principalmente entre as crianças e os adolescentes, que está transformando o desenvolvimento cognitivo destes indivíduos. Tais comportamentos, parecem se refletir na relação entre aluno e professor, influenciando na proposta educacional para adequar a novos meios de informação e o desenvolvimento para aplicação do saber. 
VII Congresso Brasileiro de Informática na Educação (CBIE 2018)

Anais do XXIV Workshop de Informática na Escola (WIE 2018)

Neste contexto, surge o nativo digital, que nasce com o contato direto com dispositivos móveis como, tablets e smartphones, com acesso a internet, jogos, redes sociais ou qualquer outro tipo de objeto e aplicação online. Assim devido a imensa quantidade de informações disponíveis na internet, as universidades são desafiadas a desenvolver novas competências para a formação do futuro egresso [dos Santos Junges and Behrens 2016].

A partir da adoção de práticas metodológicas ativas de ensino aliadas às Tecnologias Digitais de Informação e Comunicação (TDICs), o professor de hoje e os futuros professores podem tornar o processo de ensino-aprendizagem mais atraente aos olhos dos alunos. É possível prorromper e executar novos métodos didáticos a partir da união entre uso das tecnologias e os conhecimentos pedagógicos [Júnior et al. 2016].

Este trabalho analisou algumas das principais metodologias de ensino, quais sejam: Aula Expositiva Dialogada, Aprendizagem Baseada em Problemas - ABP, Aprendizagem Baseada em Times - ABT e entre outras, em destaque as metodologias ativas de ensino, que rompem com os métodos tradicionais de ensino-aprendizagem.

\section{A geração de nativos digitais}

A divisão da sociedade em gerações advém de estudos sociológicos, para agrupar indivíduos que nascem e se comportam da mesma maneira em determinada época [Ribeiro et al. 2017]. São considerados nativos digitais, aqueles que nasceram praticamente mergulhados em tecnologias, possuindo contato direto com computador e/ou celular. Cronologicamente são pessoas que nasceram em meados dos anos 90 [Prensky 2001].

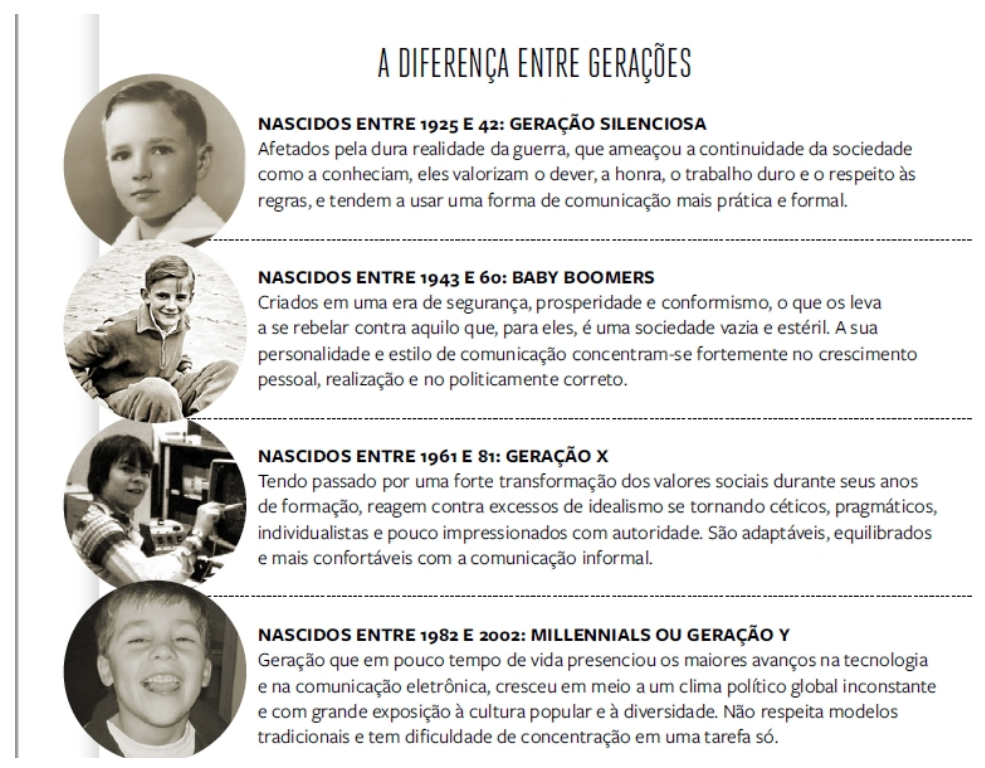

Figura 1. Diferenças entre as gerações

De acordo com a Figura 1 é possível identificar várias diferenças entre as gerações. A primeira chamada geração silenciosa, é marcada pelo autoritarismo político e forte sentimento de honra a sua nação [Prado 2015], tendo seus interesses direcionados para o trabalho. A geração Baby Boomers não está satisfeita com sua época, assim se caracteriza pela rebeldia e mudança sobre aquilo que a impede de ter paz e ser feliz. E a geração $\mathrm{X}$ deixa a formalidade entre as relações pessoais de lado, essa geração ainda possuía 
VII Congresso Brasileiro de Informática na Educação (CBIE 2018)

Anais do XXIV Workshop de Informática na Escola (WIE 2018)

resistência ao novo e ao desconhecido. Por fim, a geração Y presenciou os avanços tecnológicos no decorrer de seu amadurecimento, conseguiu se adaptar e inserir em seus costumes a tecnologia. Vale ressaltar que a geração $\mathrm{Z}$ nasceu submersa em tecnologias e aparelhos eletrônicos, ela não passou pela experiência de viver no mundo onde não existiam os celulares, a internet móvel e os tablets, é uma geração que está sempre conectada [Prado 2015].

Esta nova geração de alunos do fim do século XX, inseridos na escola, parece não estar interessada em assistir uma aula da mesma maneira todos os dias. Os nativos digitais são pessoas hiperconectadas, têm espírito empreendedor, acompanham o que acontece no mundo por meio da internet, são mais inclusivas e sem preconceito.

\section{Metodologias ativas}

Originalmente, o método ativo de aprendizagem trabalha com a experiência da criança, de modo que o professor possa incentivar seu aluno a refletir e encorajá-lo a tomar decisões, "Não quero que só o preceptor invente e fale quero que, quando chegar a vez de seu discípulo, o escute falar" [Montaigne 1972], neste sentido o aluno, assim como o professor, precisa esclarecer suas ideias e demonstrar o entendimento que adquiriu através de suas ações guiadas pelo professor.

É necessário saber qual é o método que pode atender a necessidade das instituições de ensino brasileiras diante do cenário em que o professor atua, seja no ensino médio, ensino superior ou básico e entre outros [Borges and Alencar 2014], e também trazer conceitos teóricos e vivenciados pelos alunos em seu ambiente social. A seguir são apresentadas as metodologias ativas de ensino que foram tema de estudo.

\subsection{Aula expositiva dialogada}

A Aula Expositiva Dialogada é uma aula dinâmica onde a ação e a reflexão do aluno são essenciais para o processo de aprendizagem durante o estudo, diferente da aula tradicional em que o papel do professor é depositar informações e conhecimentos [Leal et al. 2018] que não foram descobertos ou construídos pelo próprio aluno em conjunto com o seu professor.

Para uma Aula Expositiva Dialogada ser planejada, consideram-se os "Princípios norteadores de uma aula expositivo dialogada" [Coimbra 2016]: Quais são os saberes necessários para docência? Quais princípios fundamentam uma aula expositiva dialogada? Em que perspectiva trabalha a aula expositiva dialogada? Qual é o seu contexto, seus sujeitos e sua forma?

O ponto de partida para este método de aula vem do contexto cultural do aluno, isso pode possibilitar a construção de um diálogo entre aluno e professor. O método de aula expositiva dialogada convida o aluno a se expor, assimilando sua experiência com o conteúdo abordado através da prática do diálogo e da reflexão propostos pelo professor. São definidos cinco passos para a prática de aula expositiva dialogada [Coimbra 2016]:

Inspiração: Mobilização do aluno a querer determinado conhecimento;

Problematização: Desafiar o aluno. Isto consiste em questionar a realidade fazendo relação com o conteúdo que será abordado na aula;

Reflexão: Consiste no professor conseguir "provocar" o aluno a compartilhar algum saber que pode ajudar a solucionar ou amenizar o problema; 
VII Congresso Brasileiro de Informática na Educação (CBIE 2018)

Anais do XXIV Workshop de Informática na Escola (WIE 2018)

Transpiração: Realizar estudo sobre o tema através de materiais que o professor disponibiliza como livros, textos, fontes bibliográficas;

Síntese: Compartilhar o aprendizado por meio de um exercício em grupo ou individual, ou em qualquer formato (oral, escrito, avaliativo).

O objetivo da aula expositiva dialogada é propor ao professor e ao aluno que construam conhecimento de modo que atuem como sujeitos da aprendizagem e transformadores do mundo que conhecem.

\subsection{Aprendizagem Baseada em Problemas (PBL)}

A ideia de revolucionar a docência partindo de um problema surgiu com Howard Barrows em 1970, na Universidade McMaster, no departamento de medicina. Como solução para reformulação no ensino de muitos conteúdos, surgiu a ideia de usar problemas, pois os alunos estavam sobrecarregados com tantos conhecimentos que precisavam adquirir.

PBL é um método ativo de aprender, onde o professor age apresentando um problema e os alunos agem buscando a solução. Esses problemas propostos aos alunos precisam estar contextualizados com a realidade social e educacional dos alunos. $\mathrm{O}$ professor passa a conduzir a sua lição por discussões que estão centradas no problema proposto [GHMELO-SILVER and BARROWS 2006].

Tem-se os relatos da intervenção no ensino superior, utilizando PBL no curso de Psicologia da UNIDERP e ensino de Medicina na FCMUNL [Gomes et al. 2016]. A dinâmica das atividades envolve todos os alunos, vai além de memorização e repetição de conceitos. Através da pesquisa e investigação os alunos se tornam responsáveis por solucionarem os problemas. O professor faz mediação das pesquisas e das soluções que os alunos desenvolvem em grupos.

O processo da PBL segue dez passos no seu processo de aplicação [da Silva Ferraz Filho et al. 2017], quais são: (i) introdução e definição do problema, (ii) levantamento de hipóteses, (iii) tentativa de solução com conhecimento prévio, (iv) levantamento de pontos de aprendizagem, (v) aplicação dos conhecimentos no problema, (vi) compartilhamento de informação no grupo, (vii) estudo independente, (viii) planejamento do trabalho do grupo, (ix) apresentação das soluções do grupo, (x) auto-avaliação e avaliação do processo em pares.

Com isso, este processo pode ser utilizado para a promoção do aluno como sujeito ativo no seu processo de aprendizagem, abordando também uma nova perspectiva do professor como orientador e tutor no processo de ensino.

\subsection{Aprendizagem Baseada em Times (ABT)}

O objetivo deste tipo de aprendizagem é trazer o senso de trabalho colaborativo para os alunos através do desenvolvimento de habilidades e fixação e/ou avaliação dos conteúdos trabalhados em sala de aula. Esse método foi desenvolvido na Universidade de Oklahoma nos Estados Unidos, com o professor Larry Michaelsen [Michaelsen 2002]. Sua estrutura envolve o desenvolvimento de habilidades e aprendizagem colaborativa, pois os alunos são responsáveis pelo próprio aprendizado e pelo da sua equipe. Os seus conceitos são baseados no construtivismo, que faz do professor um instrutor e facilitador para instigar os alunos na sua busca pelo conhecimento significativo. 
VII Congresso Brasileiro de Informática na Educação (CBIE 2018)

Anais do XXIV Workshop de Informática na Escola (WIE 2018)

Para esta metodologia ser aplicada em sala de aula, três importantes mudanças são necessárias [Michaelsen 2002]:

1. Os objetivos primários do curso devem ir além de familiarizar os alunos com conceitos. Os objetivos incluirão assegura-los em aprender como usar os conceitos;

2. O papel do professor mudará. Ele precisará desenvolver e gerenciar o processo instrucional;

3. O papel do aluno mudará. Ao invés de passivo em relação aos conceitos, os alunos trabalharão em conjunto com seu time para aprender a utilizar o conceito.

As vantagens de usar deste método na aprendizagem traz resultados para os alunos em relação a passividade no processo de ensino [Michaelsen 2002]. Algumas destas vantagens são (a) desenvolver as competências dos alunos em alto nível, (b) promover o desenvolvimento de habilidades pessoais e em equipe, e (c) também traz vantagens para o professor, como entusiasma-los em sala de aula e a continuidade na carreira.

\subsection{Estudo de caso}

O método de estudo de caso surgiu na Escola de Direito de Harvard em 1880, por Christopher Langdell. Este método ainda passou a ser utilizado por outras áreas do conhecimento: como administração e saúde, por ser a mais adequada técnica pedagógica, capaz de fazer o estudante confrontar teoria e prática [Leal et al. 2018].

É uma atividade para resolução de um ou mais casos já elaborados, apresentado pelo professor, necessariamente envolvendo pesquisa e fontes de informações para serem analisadas, até chegar a melhor solução para o caso. É um método de estudo composto por três estágios [Rocha and LEMOS 2014] uma preparação individual, comparações das ideias dos alunos entre si e uma conclusão, onde os alunos defendem suas posições para o professor, que estará pronto para questioná-los. A aplicação deste método possui 4 etapas, sendo (1) planejamento, (2) apresentação do caso, (3) análise e debate, (4) conclusão e avaliação.

O Estudo de caso é uma metodologia ativa de ensino, que estimula os alunos a pesquisarem e refletirem sobre tomadas de decisões para solucionar o caso que estiver sendo analisado. Este método está preocupado em solucionar questões de caso sobre "como" e "por quê" que estão ligadas ao contexto social e atual na vida dos alunos [Yin 2005].

\subsection{Sala de aula invertida}

A inversão da sala de aula tem o foco em desenvolvimento de materiais didáticos para os alunos estudarem em casa. O horário de aula é utilizado para desenvolver trabalhos e/ou projetos, utilizando do conhecimento adquirido por meio de pesquisa e estudo em casa.

Essa prática faz o aluno desenvolver sua proficiência no estudo e conhecer seu ritmo de aprendizado, por exemplo, assistindo a vídeos, acesso ao mesmo conteúdo por várias vezes, pode avançar, voltar, pausar, até que entenda cada informação que o vídeo apresenta [Wang 2014]. E durante o desenvolvimento dos trabalhos na sala, o professor é instrutor e mediador entre o aluno e os conceitos que estão sendo estudados.

A Sala de aula invertida pode evoluir, fazendo com que os alunos desenvolvam, juntamente com o professor, materiais didáticos sobre o assunto estudado, possibilitando que o aluno tenha interação com o conhecimento construído, desenvolvendo formas de se expressar. 
VII Congresso Brasileiro de Informática na Educação (CBIE 2018)

Anais do XXIV Workshop de Informática na Escola (WIE 2018)

\section{Metodologia}

A pesquisa realizada é caracterizada como pesquisa quantitativa, de modo que sua abordagem seja orientada para os resultados de forma numérica. Como forma de planejamento da ação, foram elaborados planos de aula com intuito de medir o acontecimento dos eventos [Terence and Escrivão Filho 2006]. Foram elaborados questionários estruturados para utilizar como instrumento de coleta de dados, apoiado por aplicativos online.

Este realizado em uma escola pública no município de Francisco Beltrão, com uma turma de 27 alunos (homens e mulheres) do primeiro ano do Ensino Profissional de nível técnico em Curso de Formação de Docentes. As metodologias escolhidas para as aulas foram a Aprendizagem Baseada em Times e a Sala de Aula Invertida, por meio de pesquisas e a estruturação de conteúdos.

O tema das aulas ministradas para a turma foi a construção de mapas mentais e conceituais utilizando softwares online: como o Google Draw e o DIA (Dia Diagram Editor). A proposta metodológica foi que as aulas ocorressem diferentemente do modo que os alunos estavam habituados. Para começar, todas as aulas aconteceram no laboratório de informática do colégio Estadual Mário de Andrade, para que os alunos pudessem utilizar o computador e a Internet. O objetivo das aulas consistiu em guiar os alunos a produzirem conhecimento sobre o conteúdo, por meio de investigação, pensamento crítico-reflexivo e ação.

Inspirado na metodologia de sala de aula invertida, o professor enviou por $e$-mail o conteúdo da aula expositiva ministrada e solicitou aos alunos que estudassem os materiais da aula (slides, vídeos e o software em si) para posteriormente os alunos praticar este estudo prévio em da sala de aula. Na segunda aula, foi retomada a atividade da aula invertida, sendo assim, os alunos deveriam produzir seus mapas naquela aula, tendo o professor como instrutor, que pôde intermediar o conhecimento prévio do aluno com o conhecimento prático que foi construído em sala de aula.

Para o encerramento da aula e fixação do estudo teórico, foi promovido um debate com a turma sobre as dificuldades em estudar em casa, e sobre outros métodos diferentes de realizar as futuras aulas. Posteriormente, foi utilizado o Google Draw e o DIA (Dia Diagram Editor), a possibilidade de construir um mapa mental e conceitual.

Com objetivo de incentivar o raciocínio crítico e a investigação, também foram inseridos problemas a partir da realidade escolar dos alunos sobre estudos, provas, aprendizagem, entre outros, sendo orientados pelo professor. Fora ensinado como trabalhar colaborativamente na nuvem, agregando mapas mentais a este assunto, foram estudados artigos sobre utilização do celular em sala de aula e como fazer o bom uso dele. Os alunos estudavam sozinhos ou em equipes, e depois era realizado um debate entre eles e o professor, e por fim a exposição de conclusões sobre os problemas propostos.

\section{Resultados}

A presente seção descreve os aplicativos utilizados para avaliação dos alunos, o Socrative e Kahoot!, bem como descrever uma análise sobre os resultados coletados durante a experiência. 
VII Congresso Brasileiro de Informática na Educação (CBIE 2018)

Anais do XXIV Workshop de Informática na Escola (WIE 2018)

\subsection{Socrative}

O Socrative é um aplicativo de sala de aula para diversão e envolvimento efetivo. Não importa onde ou como ensina, este aplicativo permite que o professor se conecte instantaneamente com os alunos, à medida que a aprendizagem acontece.

A avaliação por meio do Socrative pode acontecer rapidamente com atividades preparadas, ou perguntas on-the-fly, que consistem em perguntas elaboradas no progresso de uma atividade ou no improviso e permitem obter uma visão imediata sobre a compreensão dos alunos, pois assim que elas são respondidas, aparece o resultado para o professor. Este aplicativo permite a criação de quizes e questionários, formais ou gamificados, utilizando o computador ou smartphone e com feedback instantâneo.

O Socrative permite ao aluno saber se acertou ou errou a questão logo após responde-la, e também, cada resposta enviada pelo aluno, o aplicativo gera uma pontuação e para o professor é gerado um documento em formato de planilha eletrônica com o resultado do desempenho dos alunos individualmente e da turma em geral.

Para fins avaliativos, foram realizados testes por meio do Socrative. A Figura 2 mostra a tela inicial do aplicativo, que contém as opções de criação de testes em forma de questionário, quiz e game.

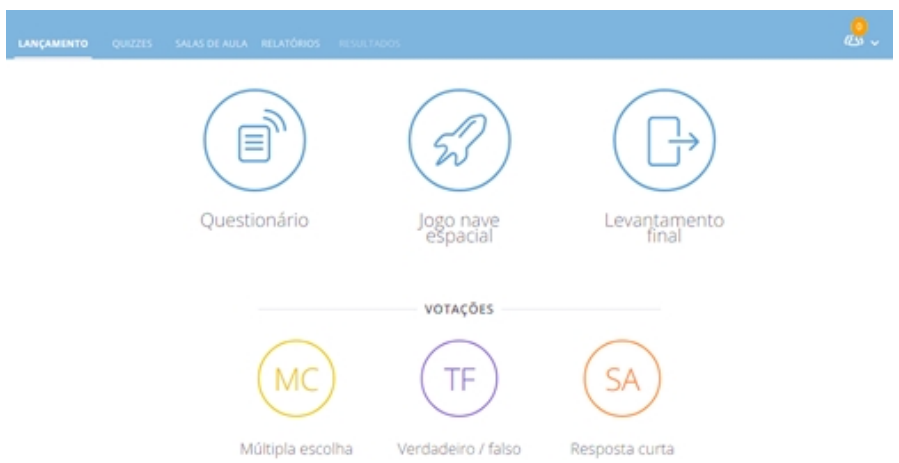

Figura 2. Tela principal de login como professor

Os alunos realizaram o teste duas vezes. Um foi individualmente e na primeira semana de aula e o segundo foi realizado em equipe no último dia de aula, assim como exemplos das etapas da metodologia TBL. Comparando os resultados das respostas individuais com as respostas das equipes, o resultado obtido em relação ao desempenho da turma foi melhor, a turma obteve média de $80 \%$ de acertos no teste, conforme ilustrado na Figura 3. As questões dissertativas resultaram em um debate sobre a utilização dos mapas mentais como apoio ao estudo e construção de conhecimento.

\subsection{Kahoot}

Como forma de avaliar o conhecimento dos alunos, foi utilizado também o aplicativo online chamado Kahoot!, que gamifica as atividades de quiz e debate gerando uma competitividade saudável [Junior 2017] entre os alunos. Este aplicativo divertido permite que o professor crie suas próprias atividades ou utilize as atividades compartilhadas por outros professores. No decorrer das atividades os alunos ganham pontos para tentar conquistar o primeiro lugar. No fim dos jogos, é gerado um pódio para os alunos, classificando os participantes em $1^{\circ}, 2^{\circ} \mathrm{e} 3^{\circ}$ lugares, como ilustrada nas Figuras 4 e 5. 
VII Congresso Brasileiro de Informática na Educação (CBIE 2018)

Anais do XXIV Workshop de Informática na Escola (WIE 2018)



Figura 3. Desempenho da turma no último teste de avaliação



Figura 4. Meus Kahoots

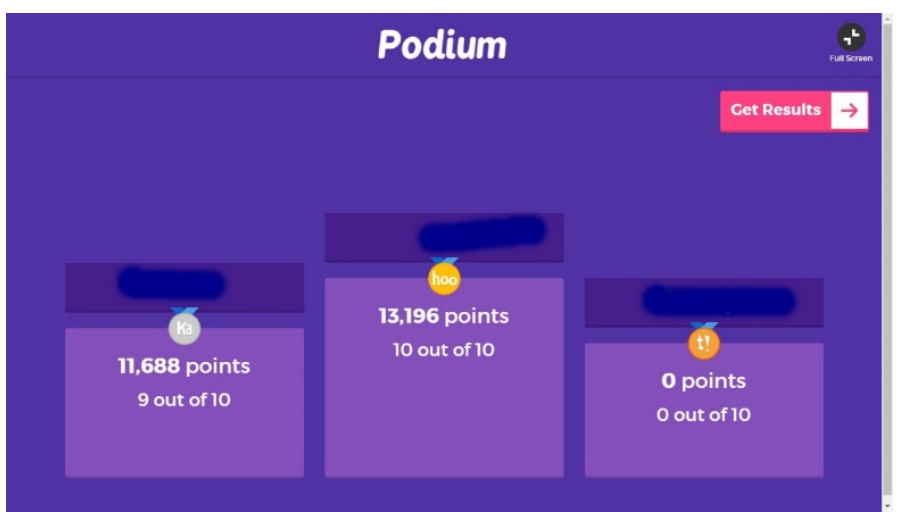

Figura 5. Pódio dos alunos no fim de jogo

A utilização do Kahoot! também teve objetivo de avaliar a aprendizagem dos alunos no decorrer das atividades. Os alunos jogaram com o Kahoot! em todas as aulas, durante todo o curso, e foi o aplicativo que os alunos demonstraram mais interesse quando comparado ao aplicativo Socrative. Foi observado no decorrer da experiência que o uso de tecnologias como o celular e o computador, mediados por métodos ativos de aprendizagem, proporcionou aos alunos um desempenho ascendente em todas as avaliações.

A partir desta experiência pode-se concluir que o aluno, por meio da investigação, pesquisa e debate, pode desenvolver conhecimento e pensamento crítico. A utilização dos aplicativos, Socrative e Kahoot!, foi essencial para o engajamento dos alunos na 
VII Congresso Brasileiro de Informática na Educação (CBIE 2018)

Anais do XXIV Workshop de Informática na Escola (WIE 2018)

participação dos testes. Os aplicativos supracitados contribuiu para os alunos como incentivo ao estudo. E em relação as competências dos alunos, a atividade também foi muito importante pois permite a autoavaliação da prática pedagógica, fazendo-nos visualizar quais conteúdos os estudantes se apropriaram com mais profundidade e quais precisam ser retomados. Além disso, o aspecto da interação social dos sujeitos envolvidos é bastante privilegiada, o que auxilia na humanização do processo educativo, fazendo com que outras dimensões sejam desenvolvidas, além da estritamente acadêmica.

\section{Considerações finais}

A utilização do computador e o celular no processo de aprendizagem proporcionou aos estudantes mais autonomia durante suas ações nas aulas. Esta experiência pôde contribuir para uma melhor relação dos alunos com os seus professores, o que demonstra uma relação estabelecida entre a aprendizagem e novos métodos de ensino. Os métodos ativos descritos neste artigo são partes do processo de ensino, que compõem as aulas do professor, contudo isto não significa que pode substituir o método de ensino tradicional.

Por meio deste relato pôde ser concluído que, gradualmente, a inserção de metodologias ativas no ensino que adotem também a tecnologia como facilitadora do processo de aprendizagem, pode aprimorar o desenvolvimento do conhecimento, pois ela provoca uma mudança de comportamento do aluno e do professor, trazendo problemas reais dentro do contexto escolar e informações e reflexões a partir da vivência do aluno.

Contudo, as metodologias ativas, não são a solução para todos os problemas que a educação possui. Também pôde ser concluído por meio da experiência que um método inovador de ensino não é capaz sozinho de transformar todo um sistema educacional. É necessário refletir que a inserção de novas tecnologias, bem como diferentes metodologias de ensino dentro da sala de aula, requer tempo, adaptação e reflexão sobre como inserir a cultura digital no ambiente escolar.

A tecnologia não pode resolver todos os problemas, mas é possível atingir níveis satisfatórios de trabalho com a nova geração quando o professor aprende a usá-la em sua prática docente.

\section{Referências}

Borges, T. S. and Alencar, G. (2014). Metodologias ativas na promoção da formação crítica do estudante: o uso das metodologias ativas como recurso didático na formação crítica do estudante do ensino superior. Cairu em Revista, 3(04):119-143.

Coimbra, C. L. (2016). A aula expositiva dialogada em uma perspectiva freireana. Anais do III Congresso Nacional de Formação de Professores (cnfp) e XIII Congresso Estadual Paulista Sobre Formação de Educadores (cepfe), 3(04):1-13.

da Silva Ferraz Filho, B., dos Santos, A. C., da Silva, R. O., Bittencourt, W., Peixoto, R. N., and Marcelino, R. (2017). Aprendizagem baseada em problema (pbl): Uma inovação educacional? Revista Cesumar-Ciências Humanas e Sociais Aplicadas, 22(2):403424.

dos Santos Junges, K. and Behrens, M. A. (2016). Uma formação pedagógica inovadora como caminho para a construção de saberes docentes no ensino superior. Educar em Revista, 32(59):211-229. 
VII Congresso Brasileiro de Informática na Educação (CBIE 2018)

Anais do XXIV Workshop de Informática na Escola (WIE 2018)

Fiorio, R., Esperandim, R. J., Silva, F. A., Varela, P. J., Leite, M. D., and Reinaldo, F. A. F. (2014). Uma experiência prática da inserção da robótica e seus beneficios como ferramenta educativa em escolas públicas. In Brazilian Symposium on Computers in Education (Simpósio Brasileiro de Informática na Educação-SBIE), volume 25, page 1223.

GHMELO-SILVER, C. E. and BARROWS, H. S. (2006). Goals and strategies of a problembased learning facilitator. Interdisciplinary Journal of Problem-Based Learning, 1(01):-

Gomes, R., Brito, E., and Varela, A. (2016). A intervenÇÃ̃o na formaÇÃo no ensino superior: A aprendizagem baseada em problemas (pbl). Interacções, 3(04):47-50.

Junior, J. B. B. (2017). O aplicativo kahoot na educação: Verificando os conhecimentos dos alunos em tempo real. pages 1587-1602.

Júnior, M., Freitas, F. R., and de Lima, J. O. G. (2016). Os saberes docentes e as práticas pedagógicas de licenciandos em informática: um estudo diagnóstico. Revista Brasileira de Informática na Educação, 24(1).

Leal, E. A., Miranda, J., and Nova, S. P. d. C. C. (2018). Revolucionando a sala de aula: como envolver os estudantes aplicando as técnicas de metodologias ativas de aprendizagem.

Michaelsen, L. K. (2002). Getting started with team learning. Team learning: A transformative use of small groups. Westport, CT: Greenwood.

Montaigne, M. (1972). Ensaios. Abril Cultural, São Paulo.

Prado, A. (2015). Entendendo o aluno do século 21 e como ensinar a essa nova geração. Geekie, São Paulo.

Prensky, M. (2001). Nativos digitais, imigrantes digitais. On the horizon, 9(5):1-6.

Reinaldo, F., Magalhães, D., Reis, L., Gaffuri, S., Freddo, A., and Hallal, R. (2016). Uso de smartphones na educação: Avaliação por grupos focais. CIAIQ2016, 1.

Ribeiro, A. G., Altino Filho, H. V., and Alves, L. M. N. (2017). A tecnologia como instrumento facilitador da relação ensino aprendizagem de matemática. Anais do Seminário Científico da FACIG, (2).

Rocha, H. M. and LEMOS, W. d. M. (2014). Metodologias ativas: do que estamos falando? base conceitual e relato de pesquisa em andamento. IX Simpósio Pedagógico e Pesquisas em Comunicação. Resende, Brazil: Associação Educacional Dom Boston, page 12.

Terence, A. C. F. and Escrivão Filho, E. (2006). Abordagem quantitativa, qualitativa e a utilização da pesquisa-ação nos estudos organizacionais. Encontro Nacional de Engenharia de Produção, 26:1-9.

Wang, Z. (2014). Research on teaching design and application of flipped classroom mode. In Proceedings of the 2014 International Conference on Education Technology and Information System (ICETIS 2014). Citeseer.

Yin, R. K. (2005). Estudo de caso: planejamento e métodos. 